\title{
ANALISA ASAM LEMAK DALAM MINYAK KELAPA MURNI (VCO) DENGAN DUA PERALATAN KROMATOGRAFI GAS
}

\author{
Julius Pontoh ${ }^{1)}$ dan Nancy T.N. Buyung ${ }^{2)}$ \\ e-mail:pontohjulius@yahoo.com \\ ${ }^{1)}$ Program Studi Kimia FMIPA Universitas Sam Ratulangi, Manado 95115 \\ ${ }^{2)}$ Alumni Program Studi Kimia FMIPA Universitas Sam Ratulangi, Manado 95119
}

\begin{abstract}
ABSTRAK
Komposisi asam asam lemak dalam minyak kelapa sangat penting untuk menilai kualitas dari minyak tersebut. Untuk minyak kelapa, komposisi dari asam lemak rantai menengah seperti kaprilik, kaprat dan laurat menjadi asam asam lemak penting. Di Indonesia ada dua laboratorium yang banyak digunakan untuk menganalisa asam asam lemak dalam minyak kelapa murni. Tujuan penelitian ini adalah untuk membandingkan kedua laboratorium tersebut dalam menganalisa asam asam lemak. Kromatogram dari Laboratorium pertama menunjukan garis dasar yang ebih baik, tetapi tidak dapat mendeteksi asam stearat. Waktu retensi asam asam lemak dalam kedua komatogram sangat berbeda. Demikian juga dengan luas puncak dari asam asam lemak berbeda dalam kedua kromatogram. Namun demikian, persentasi luas pencak dari masing masing asam lemak dalam kedua kromatogram hampir sama.
\end{abstract}

Kata kunci: kromatogarafi gas, waktu retensi

\section{FATTY ACID ANALYSIS IN VIRGIN COCONUT OIL (VCO) WITH TWO TYPES GAS CHROMATOGRAPHY}

\begin{abstract}
Fatty acid composition in coconut oil is very important to evaluate the quality of the oil. For coconut oil, the composition of medium length of fatty acids such as caprylic, capric and lauric acids are the interest of the oil. To date, this fatty acid composition is the best to be analyzed by gas chromatography. In Indonesia, there are two laboratories used to analyze the fatty acids. The purpose of this study is to compare the two laboratories in the analysis the compounds. Samples of commercial coconut oils were treated with acid and base to converted into Fatty acid methyl ester. The derivatives were extracted with hexane and ready to be send to the laboratories. The results show the chromatogram of the two laboratories is totally difference. The chromatograph from Laboratory 1 showed very good base line but there was no stearic fatty acid peak shown The retention time for the same fatty acids is different. Peak areas among the same fatty acids are totally different between the two laboratories, but the percentage for each fatty acid is almost the same.
\end{abstract}

Keywords: gas chromatography, retention time

\section{PENDAHULUAN}

\section{Latar Belakang}

Minyak kelapa murni virgin coconut oil (VCO) merupakan hasil olahan dari daging buah kelapa segar (non kopra) yang dalam pengolahannya tidak melalui proses kimiawi dan tidak menggunakan pemanasan tinggi sehingga minyak yang dihasilkan berwarna bening (jernih) dan beraroma khas kelapa. Menurut standar internasional yang dikeluarkan oleh APCC (Asian Pacific Coconut Community) bahwa kandungan asam laurat VCO adalah 43-53\%; kandungan asam lemak bebas sangat rendah yaitu $0,5 \%$; serta kadar airnya mencapai $0,1-0,5 \%$ (APCC, 2004). Komposisi asam lemak tertinggi dalam minyak kelapa murni adalah asam laurat yang berfungsi memberi gizi serta melindungi tubuh dari penyakit menular dan penyakit degeneratif (Sutarmi, 2005). Minyak disebut juga trigliserida atau 
triasilgliserol,dan pada suhu kamar minyak bersifat cair(Fessenden \& Fessenden,1990).

Komposisi asam lemak minyak kelapa terdiri dari asam lemak jenuh yaitu asam kaproat $(0,0-0,8 \%)$, asam kaprilat $(5,5$ $-9,5 \%)$,asam kaprat $(4,5-9,5)$ asam laurat $(44,0-52,0 \%)$, asam miristat $(13,0-19,0 \%)$, asam palmitat $(7,5-10,5 \%)$, asam stearat $(1,0-1,3 \%)$ dan asam arachidat $(0,0-0,4 \%)$ dan asam lemak tidak jenuh yaitu asam palmitoleat $(0,0-1,3 \%)$, asam oleat $(5,8-$ $8,0 \%)$, asam linoleat $(1,5-2,5 \%)$ (Zapsalis dan Beck, 1985 ).

Asam lemak merupakan kelompok bahan alam yang sangat kompleks untuk dilakukan analisis langsung.Hingga saat ini tidak ada satu metode yang sederhana untuk mengidentifikasikan asam lemak. Kromatografi gas dapat dipakai untuk melakukan analisis asam lemak pada minyak dalam bentuk metil esternya,dalam analisis ini diperlukan beberapa teknik yang dapat menampilkan pemisahan metil ester penyusun minyak dalam kolom kromatografi dengan baik,senyawa metil ester dari asam lemak suatu minyak mempunyai perbedaan titik didih yang kecil sehingga pemisahan beberapa metil ester pada suhu yang konstan akan mengalami kesulitan. Oleh sebab itu diperlukan teknik suhu terprogram untuk analisis metil ester asam lemak dari minyak (Anwar,1996).

Untuk menentukan jenis dan komposisi asam lemak yang terkandung dalam VCO dapat dilakukan dengan proses esterifikasi yang menghasilkan metil ester, kemudian diikuti dengan fraksinasi. Fraksinasi ini bisa dilakukan dengan cara kromatografi gas,kromatografi lapis tipis atau menggunakan spektrofotometer dengan sinar inframerah (Winarno 2002).

Kromatografi gas merupakan metode pemisahan suatu campuran menjadi komponen-komponen berdasarkan interaksi tersebut yaitu fase gerak dan fase diam. Fase gerak berupa gas yang stabil sedangkan fase diam bisa zat padat (GSC = Gas Solid Chromatography), atau zat cair (GLC = Gas Liquid Chromatography). Cuplikan yang dapat dipisahkan dengan metode ini harus mudah menguap, Metode ini bekerja sangat cepat sehingga dalam waktu beberapa detik dapat memisahkan secara sempurna.Cuplikan dalam bentuk uap dibawa oleh aliran gas ke dalam kolom pemisah, hasil pemisahan dapat dianalisis dari kromatogram. Kromatogram adalah kurva yang diperoleh dari pengukuran kromatografi, dan alat yang digunakan disebut kromatograf (Hendayana, 1994)

Menurut Robards, dkk (1994) setiap alat GC mempunyai karakteristik tertentu yang dipengaruhi oleh disain (geometri) alat seperti panjang kolom, diameter kolom,dan kondisi operasi seperti kecepatan gas dan suhu oven. Parameter ini sangat menentukan resolusi dari asam lemak dan keakuratan analisa.Dengan demikian perlu diketahui penampilan analisa asam lemak dari VCO dengan menggunakan kedua alat ini.Pada saat ini sebagian sampel untuk penentuan asam lemak dilakukan di laboratorium pangan IPB dan kimia organik UGM.

\section{Tujuan Penelitian}

Untuk mengetahui performance hasil analisa komposisi asam lemak dari VCO untuk masing-masing alat kromatografi gas di dua laboratorium pangan yang biasanya menganalisa asam asam lemak VCO.

\section{METODOLOGI PENELITIAN}

\section{Bahan dan alat}

Bahan yang digunakan adalah minyak kelapa murni (VCO), $\mathrm{H}_{2} \mathrm{SO}_{4}$ metanolik, $\mathrm{NaOH}$ metanolik, metanol, dan heksan.Sedangkan alat yang digunakan adalah termometer, neraca analitik, alat-alat gelas laboratorium, waterbath, pipet dan peralatan kromatografi gas.

\section{Penyiapan sampel}

\section{Transesterifikasi Asam (Laureles, et al.,} 2002)

Sebanyak $2 \mathrm{~mL}$ heksan ditambahkan dalam 0,1 gr VCO lalu dikocok hingga bercampur. Selanjutnya metanolik $\mathrm{H}_{2} \mathrm{SO}_{4}$ ditambahkan sebanyak $0,4 \mathrm{~mL}$ dan kocok selama 10 detik. Setelah itu, larutan ditempatkan dalam waterbath yang telah diukur suhunya yaitu $50^{\circ} \mathrm{C}$ selama 60 detik kemudian diangkat dikocok selama 10 detik. Selanjutnya ditambahkan metanolik $\mathrm{NaOH}$ sebanyak $0,4 \mathrm{ml}$ dan dikocok selama beberapa detik hingga bercampur kemudian didiamkan beberapa saat hingga terbentuk dua lapisan. Lapisan metil ester dipisahkan 
dan digunakan untuk analisa kromatografi gas.

\subsubsection{Transesterifikasi Basa \\ (Laureles, et al., 2002)}

Sebanyak $2 \mathrm{~mL}$ heksan ditambahkan dalam 0,1 gr VCO lalu dikocok hingga bercampur. Selanjutnya ditambahkan metanolik NaOHsebanyak $0,4 \mathrm{~mL}$ dan dikocok selama 10 detik kemudian ditempatkan dalam waterbath yang telah diukur suhunya yaitu $50^{\circ} \mathrm{C}$ selama 60 detik lalu diangkat kemudian dikocok selama 10 detik. Setelah itu, metanolik $\mathrm{H}_{2} \mathrm{SO}_{4}$ ditambahkan sebanyak $0,4 \mathrm{~mL}$ dan larutan dikocok selama beberapa detik hingga bercampur. Larutan didiamkan selama beberapa saat hingga terbentuk dua lapisan, lapisan metil ester dipisahkan dan digunakan untuk analisa kromatografi gas.

\section{Transesterifikasi asam (Christie, 1993)}

Ke dalam labu leher tiga kapasitas $250 \mathrm{ml}$ dimasukkan $25 \mathrm{~g}$ VCO sambil diaduk dengan pengaduk magnetik.Sebanyak $5 \mathrm{~mL}$ $\mathrm{H}_{2} \mathrm{SO}_{4}$ dilarutkandalam $100 \mathrm{~mL}$ metanol kemudian campuran larutan ini melalui corong penetes ditambahkan tetes demi tetes ke dalam VCO. Selanjutnya larutan direfluks selama 10 jam dengan pemanasan pada suhu $65^{\circ} \mathrm{C}$. Larutan hasil refluks kemudian diekstraksi dengan petroleum eter dan aquades.Fase organik yang diperoleh ditambahkan $\mathrm{Na}_{2} \mathrm{SO}_{4}$ anhidrous kemudian disaring.Filtrat yang diperoleh selanjutnya diuapkan untuk menghilangkan pelarut.Residunya merupakan hasil metil ester asam lemak kemudian dianalisis dengan menggunakan kromatografi gas.

\section{Tansesterifikasi basa (Christie, 1993)}

Ke dalam labu leher tiga kapasitas $250 \mathrm{ml}$ dimasukkan $25 \mathrm{~g}$ VCO sambil diaduk dengan pengaduk magnetik.Sebanyak $5 \mathrm{~g}$ $\mathrm{NaOH}$ dilarutkan dalam $100 \mathrm{~mL}$ metanol kemudian campuran larutan ini melalui corong penetes ditambahkan tetes demi tetes ke dalam VCO. Selanjutnya larutan direfluks selama 10 jam dengan pemanasan pada suhu $65^{\circ} \mathrm{C}$. Larutan hasil refluks kemudian diekstraksi dengan petroleum eter dan aquades.Fase organik yang diperoleh ditambahkan $\mathrm{Na}_{2} \mathrm{SO}_{4}$ anhidrous kemudian
disaring.Filtrat yang diperoleh selanjutnya diuapkan untuk menghilangkan pelarut.Residunya merupakan hasil metil ester asam lemak kemudian dianalisis dengan menggunakan kromatografi gas.

\section{Esterifikasi (IUPAC, 1987 dikerjakan oleh lab. Pangan IPB)}

Ke dalam 0,1 grVCO ditambahkan nheksan $1 \mathrm{ml}$ kemudian divortex dan ditambahkan $\mathrm{NaOH} 1,5 \mathrm{ml}$. Setelah itu dipanaskan pada suhu $80^{\circ} \mathrm{C}$ selama 5 menit kemudian didinginkan. Selanjutnya ditambahkan $\mathrm{BF}_{3}$ dalam metanol sebanyak 2 $\mathrm{ml}$ serta dipanaskan pada suhu $80^{\circ} \mathrm{C}$ selama 25 menit. Kemudian didinginkan dan ditambahkan berturut-turut $\mathrm{n}$-heksan $1,5 \mathrm{ml}$ dan $3 \mathrm{ml}$ larutan $\mathrm{NaCL}$ jenuh. Diambil lapisan atas, ditambahkan $\mathrm{Na}_{2} \mathrm{SO}_{4}$ anhidrous, disaring dan siap disuntikkan pada alat kromatografi gas.

\section{Prosedur Kerja Kromatografi Gas}

Sampel diinjeksikan melalui suatu sampel injection port yang temperaturnya dapat diatur, senyawa-senyawa dalam sampel akan menguap dan akan dibawa oleh gas pengemban menuju kolom. Zat terlarut akan teradsorpsi pada bagian atas kolom oleh fase diam, kemudian akan merambat dengan laju rambatan masing-masing komponen yang sesuai dengan nilai $K_{d}$ masing-masing komponen tersebut (Khopkar, 1990).

Komponen-komponen tersebut terelusi sesuai dengan urut-urutan makin besarnya nilai koefisien partisi $\left(\mathrm{K}_{\mathrm{d}}\right)$ menuju ke detektor. Detektor mencatat sederetan sinyal yang timbul akibat perubahan konsentrasi dan perbedaan laju elusi. Pada alat pencatat sinyal ini akan tampak sebagai kurva antara waktu terhadap komposisi aliran gas pembawa.

Terdapat perbedaan kondisi alat yang digunakan pada kedua laboratorium, diantaranya jenis kolom yang digunakan, pengaturan suhu, panjang kolom, dimana semakin panjang kolom yang digunakan semakin baik pula pemisahan. 
Kondisi Alat Lab I

$\begin{array}{ll}\text { Gas pembawa } & : \text { He } \\ \text { Kolom } & : \text { Kapiler HPs } \\ & \text { (95\% dimetil dan 5\% } \\ \text { difenilpolisiloxane) } \\ \text { Panjang kolom } & : 30 \mathrm{~m} \\ \text { Suhu awal } & : 120^{\circ} \mathrm{C} \\ \text { Suhu akhir } & : 280^{\circ} \mathrm{C} \\ \text { Jenis detektor } & : \text { FID }\end{array}$

\section{HASIL DAN PEMBAHASAN}

Hasil analisa asam lemak dengan menggunakan kromatografi gas untuk Laboratorium 1 dan 2 dapat di lihat dalam Gambar 1 dan 2. Dari gambar ini terlihat adanya perbedaan yang jelas antara kedua kromatogram.Perbedaan yang sangat jelas adalah keadaan base line yang sangat baik pada Lab 1 dibandingkan dengan Lab 2.Pada Lab ke 2, base line tidak terlalu baik pada awal watu retensi, sekalipun keadaan seperti ini adalah wajar dalam analisa dengan kromatografi gas. Perbedaan lain meliputi waktu retensi, luas puncak dan persen luas puncak.

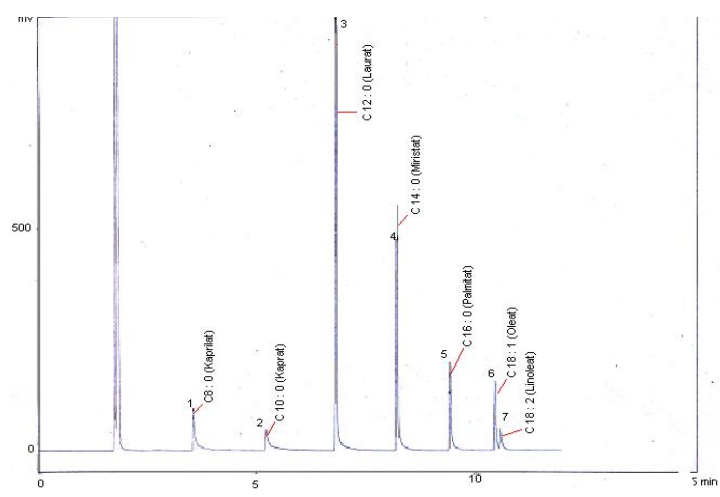

Gambar 1. Transestrifikasi Asam Hasil Analisis Laboratorium 1

\section{Waktu Retensi}

Terdapat tujuh jenis asam lemak yang teridentifikasi pada metil ester VCO yang dianalisis pada Lab I dan delapan jenis asam lemak yang teridentifikasi pada metil ester VCO yang dianalisis pada Lab 2. Waktu Retensi untuk masing-masing asam lemak disajikan pada Tabel 1.
Kondisi Alat Lab II

Gas pembawa : He

Kolom : Kapiler DB 23

(90\% bis sianopropil

dan $\quad 10 \quad \%$

fenilsianopropil

Panjang kolom Polisiloxane

Suhu awal $\quad: 50 \mathrm{~m}$

Suhu akhir $\quad: 120^{\circ} \mathrm{C}$

Jenis detektor $\quad: 230^{\circ} \mathrm{C}$

: FID

Waktu retensi adalah waktu yang dibutuhkan oleh asam lemak untuk muncul didetektor yang dihitung dari waktu injeksi. Pada praktisnya waktu retensi diperoleh dari titik injeksi sampel sampai puncak asam lemak terelusi (Khopkar, 1990).

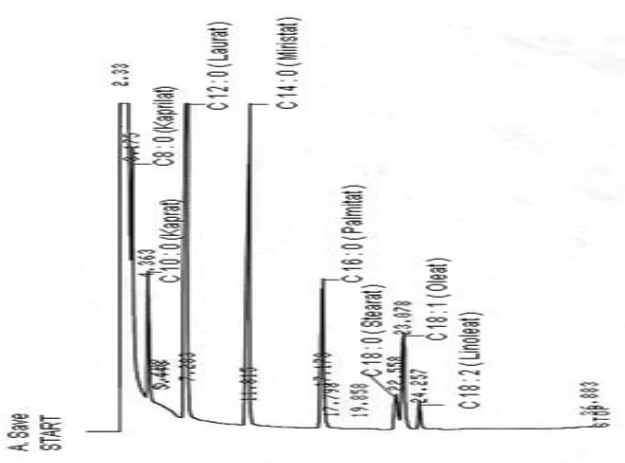

Gambar 2. Kromatogram Transesterifikasi Asam Hasil Analisis Laboratorium 2

Waktu retensi untuk masing-masing asam lemak disetiap lab hampir sama (Tabel1). Waktu retensi asam lemak rantai pendek (kaprilat) di Lab 1 adalah 3,54-3,60 menit sedangkan waktu retensi untuk asam (kaprilat) di Lab 2 adalah 3,17-3,19 menit, adapun waktu retensi asam lemak rantai panjang (linoleat) di Lab 1 adalah 10,5110,54 menit sedangkan waktu retensi untuk asam (linoleat) di Lab 2 adalah 24,25-24,43 menit. Hal ini menunjukkan konsistensi alat yang digunakan oleh setiap Lab cukup tinggi.

Pada tabel 1 dapat dilihat bahwa asam stearat tidak muncul ketika dianalisis di Lab 1 tetapi muncul ketika dianalisis di Lab 2. Tidak munculnya asam stearat ketika dianalisa di Lab 1 mungkin karena asam stearat tertinggal didalam kolom.

Garis dasar kromatogram pada Lab 1 lebih baik, mulai dari keluarnya pelarut sampai 
pada akhir analisa, dibandingkan garis dasar kromatogram pada Lab 2 yang memperlihatkan adanya gangguan terhadap garis dasar. Sejak keluarnya sampel pelarut garis dasar tidak segera turun tetapi turun secara lambat. Dengan demikian resolusi antara asam kaprilat dengan pelarut tidak baik (berhimpit). Hal ini tentunya akan mempengaruhi perhitungan luas puncak, kondisi ini perlu diperbaiki misalnya dengan menurunkan suhu awal $\left(\leq 120{ }^{\circ} \mathrm{C}\right)$. Adanya perbedaan garis dasar antara Lab 1 dan 2 mungkin disebabkan karena jenis kolom yang berbeda.

Tabel 1.Waktu Retensi Untuk Masing-Masing Metode dan Laboratorium

\begin{tabular}{|c|c|c|c|c|c|c|c|c|c|c|}
\hline & \multirow{5}{*}{ Asam Lemak } & \multicolumn{9}{|c|}{ Waktu Retensi } \\
\hline & & \multirow{3}{*}{\multicolumn{2}{|c|}{$\begin{array}{c}\text { Asam } \\
\text { Transesterifikas } \\
\text { i } \\
\text { Christie }\end{array}$}} & \multicolumn{2}{|c|}{ Asam } & \multicolumn{2}{|c|}{ Basa } & \multicolumn{2}{|c|}{ Basa } & \multirow{4}{*}{$\begin{array}{l}\text { Esterifi } \\
\text { kasi } \\
\text { IUPAC }\end{array}$} \\
\hline & & & & \multirow{2}{*}{\multicolumn{2}{|c|}{$\begin{array}{c}\text { Transesterifikas } \\
\text { Laurelles }\end{array}$}} & \multirow{2}{*}{\multicolumn{2}{|c|}{$\begin{array}{c}\text { Transesterifikas } \\
\text { Christie }\end{array}$}} & \multirow{2}{*}{\multicolumn{2}{|c|}{$\begin{array}{c}\text { Transesterifikasi } \\
\text { Laurelles }\end{array}$}} & \\
\hline & & & & & & & & & & \\
\hline & & LA I & LA II & NA I & NA II & LB I & LB II & NB I & NB II & \\
\hline \multirow{8}{*}{$\begin{array}{c}\text { Lab } \\
\text { I }\end{array}$} & Kaprilat & 3,54 & 3,54 & 3,56 & 3,57 & 3,60 & 3,58 & 3,56 & 3,55 & \\
\hline & Kaprat & 5,18 & 5,18 & 5,21 & 5,22 & 5,19 & 5,18 & 5,21 & 5,20 & \\
\hline & Laurat & 6,80 & 6,80 & 6,80 & 6,80 & 6,80 & 6,79 & $\mathbf{6 , 8 0}$ & 6,80 & \\
\hline & Miristat & 8,18 & 8,18 & 8,18 & 8,18 & 8,18 & 8,17 & 8,19 & 8,18 & \\
\hline & Palmitat & 9,40 & 9,39 & 9,41 & 9,41 & 9,39 & 9,38 & $\mathbf{9 , 4 3}$ & 9,40 & \\
\hline & Stearat & & & & & & & & & \\
\hline & Oleat & 10,40 & 10,40 & 10,41 & 10,41 & 10,40 & 10,39 & 10,41 & 10,41 & \\
\hline & Linoleat & 10,51 & 10,51 & 10,54 & 10,54 & 10,51 & 10,50 & 10,54 & 10,53 & \\
\hline \multirow{8}{*}{$\begin{array}{l}\text { Lab } \\
\text { II }\end{array}$} & Kaprilat & 3,19 & & 3,17 & & 3,17 & & 3,17 & & 3,18 \\
\hline & Kaprat & 4,36 & & 4,36 & & 4,34 & & 4,35 & & 4,36 \\
\hline & Laurat & 7,34 & & 7,28 & & 7,34 & & 7,29 & & 7,52 \\
\hline & Miristat & 11,87 & & 11,81 & & 11,87 & & 11,83 & & 12,06 \\
\hline & Palmitat & 17,31 & & 17,17 & & 17,32 & & 17,27 & & 17,43 \\
\hline & Stearat & 22,69 & & 22,55 & & 22,67 & & 22,63 & & 22,84 \\
\hline & Oleat & 23,19 & & 23,07 & & 23,25 & & 23,20 & & 23,38 \\
\hline & Linoleat & 24,36 & & 24,25 & & 24,35 & & 24,32 & & 24,43 \\
\hline
\end{tabular}

\section{Luas Puncak (Peak Area)}

Terdapat tujuhjenis asam lemak yang teridentifikasi pada metil ester VCO yang dianalisis Lab 1 dan 8 jenis asam lemak yang teridentifikasi pada metil ester VCO yang dianalisis pada Lab 2 dengan perbandingan luas puncak disajikan dalam Tabel 2.

Puncak area ( luas puncak ) adalah luas area dibawah puncak yang ditentukan oleh tinggi puncak dan lebar dasar puncak. Makin tinggi puncak dan makin lebar dasar puncak, makin besar luas puncak. Luas puncak untuk setiap asam lemak dan metode metilasi dapat dilihat pada Tabel 2. Dimana luas puncak terbesar dihasilkan oleh asam laurat diikuti miristat, palmitat, oleat, kaprat, kaprilat dan yang terkecil adalah linoleat

Secara umum luas puncak dari Lab 1 lebih tinggi dari Lab 2 misalnya untuk asam kaprilat luas puncak pada Lab 1 adalah 424363 sedangkan pada Lab 2 adalah 12085. Dengan demikian luas puncak untuk asam kaprilat di Lab 1 adalah sekitar 35 kali dibanding Lab 2. Luas puncak untuk asam laurat di Lab 1 adalah 2525125 sedangkan pada Lab 2 adalah 105582. Dengan demikian luas puncak asam laurat di Lab 1 adalah 25 kali dibandingkan Lab 2. Tingginya luas puncak di Lab 1 disebabkan oleh sensitifitas 
integrator di Lab 1 lebih tinggi dari sensitifitas di Lab 2. Sensitifitas ditentukan oleh besarnya setting dari treshold. Treshold adalah penguatan signal oleh komputer (Robards et.al, 1994 ).

Tabel 2. Luas Puncak Untuk Masing-Masing Metode dan Laboratorium

\begin{tabular}{|c|c|c|c|c|c|c|c|c|c|c|}
\hline \multirow[t]{4}{*}{ - } & \multirow{4}{*}{$\begin{array}{l}\text { Asam } \\
\text { Lemak }\end{array}$} & \multicolumn{9}{|c|}{ Luas Puncak } \\
\hline & & \multicolumn{2}{|c|}{ Asam } & \multicolumn{2}{|c|}{ Asam } & \multicolumn{2}{|c|}{ Basa } & \multicolumn{2}{|c|}{ Basa } & \multirow[b]{2}{*}{$\begin{array}{c}\text { Esterifi } \\
\text { kasi }\end{array}$} \\
\hline & & \multicolumn{2}{|c|}{$\begin{array}{c}\text { Transesterifikasi } \\
\text { Christie }\end{array}$} & \multicolumn{2}{|c|}{$\begin{array}{c}\text { Transesterifikasi } \\
\text { Laurelles }\end{array}$} & \multicolumn{2}{|c|}{$\begin{array}{c}\text { Transesterifikasi } \\
\text { Christie }\end{array}$} & \multicolumn{2}{|c|}{$\begin{array}{c}\text { Transesterifikasi } \\
\text { Laurelles }\end{array}$} & \\
\hline & & LA I & LA II & NA I & NA II & LB I & LB II & NB I & NB II & \\
\hline \multirow{8}{*}{$\begin{array}{c}\text { Lab } \\
\text { I }\end{array}$} & Kaprilat & 507107 & 539154 & 359379 & 335500 & 131293 & 182739 & 424363 & 483244 & \\
\hline & Kaprat & $\mathbf{5 7 4 9 7 7}$ & 568408 & 258520 & 229983 & 401175 & 363438 & 303250 & 380707 & \\
\hline & Laurat & 3705131 & 3643126 & 2392904 & 2207025 & 3149850 & 3172670 & 2525124 & 2696779 & \\
\hline & Miristat & 2269079 & 2258467 & 1000989 & 864130 & 23325 & 532048 & 1097547 & 1211142 & \\
\hline & Palmitat & 1340878 & 1361305 & 474312 & 413043 & 1658813 & 1745806 & 520952 & 597342 & \\
\hline & Stearat & & & & & & & & & \\
\hline & Oleat & 996873 & 988130 & 367596 & 324428 & 642738 & 731664 & 415810 & 487396 & \\
\hline & Linoleat & 437614 & 445434 & 154806 & 138767 & 246372 & 292724 & 171893 & 209611 & \\
\hline \multirow{8}{*}{$\begin{array}{c}\text { Lab } \\
\text { II }\end{array}$} & Kaprilat & 6650 & & 7610 & & 2953 & & 12085 & & 30682 \\
\hline & Kaprat & 8989 & & 8500 & & 9765 & & 12952 & & 26845 \\
\hline & Laurat & 80617 & & 69197 & & 88956 & & 105582 & & 204168 \\
\hline & Miristat & 35230 & & 27662 & & 35190 & & 42898 & & 80408 \\
\hline & Palmitat & 19477 & & 13927 & & 16917 & & 21839 & & 40470 \\
\hline & Stearat & 5829 & & 4162 & & 4914 & & 6425 & & 12889 \\
\hline & Oleat & 13672 & & 9793 & & 113282 & & 15594 & & 27618 \\
\hline & Linoleat & 1918 & & 2087 & & 2676 & & 3370 & & 6479 \\
\hline
\end{tabular}

Luas pincak berhubungan dengan konsentrasi senyawa, dimana makin luas puncak, makin tinggi konsentrasinya. Luas puncak ditentukan juga oleh faktor sensitifitas detektor dan keakuratan alat pengolah data.

\section{Persen Luas Puncak}

Terdapat tujuh jenis asam lemak yang teridentifikasi pada metil ester VCO yang dianalisis pada Lab 1 dan delapan jenis asam lemak yang teridentifikasi pada metil ester VCO yang dianalisis pada Lab 2, dengan perbandingan konsentrasi disajikan dalam Tabel 3.

Persen puncak area (\% luas puncak) adalah perbandingan antara luas puncak dari masing - masing asam lemak terhadap total luas puncak dari seluruh asam lemak. Persen luas puncak dapat digunakan untuk menetapkan perbandingan konsentrasi asam lemak. Bila total konsentrasi asam lemak diketahui maka konsentrasi masing-masing asam lemak dapat ditentukan. Pada Tabel 3 diatas dapat dilihat bahwa persen luas puncak asam lemak laurat yang dianalisa di Lab 1 lebih rendah yaitu 37,68 \% sampai 48-89\% sedangkan konsentrasi asam lemak yang sama dihasilkan dari lab 2 adalah berkisar $46,76 \%$ sampai $51,49 \%$. Nilai ini hampir sama dengan konsentrasi asam laurat yang diperoleh dengan metode IUPAC. Nilai ini juga hampir sama dengan konsentrasi asam laurat yang telah ada sebelumnya. 
Persen luas puncak dari asam kaprilat yang diperoleh pada Lab 1 lebih tinggi dari Lab 2. Sedangkan asam kaprat yang diperoleh di Lab 1 dan 2 hampir sama. Hal ini mungkin disebabkan karena garis dasar pada Lab 1 lebih baik dari Lab 2. Garis dasar yang baik akan menyebabkan perhitungan luas puncak yang lebih baik.

Tabel 3. Persen Luas Puncak Untuk Masing-Masing Metode dan Laboratorium

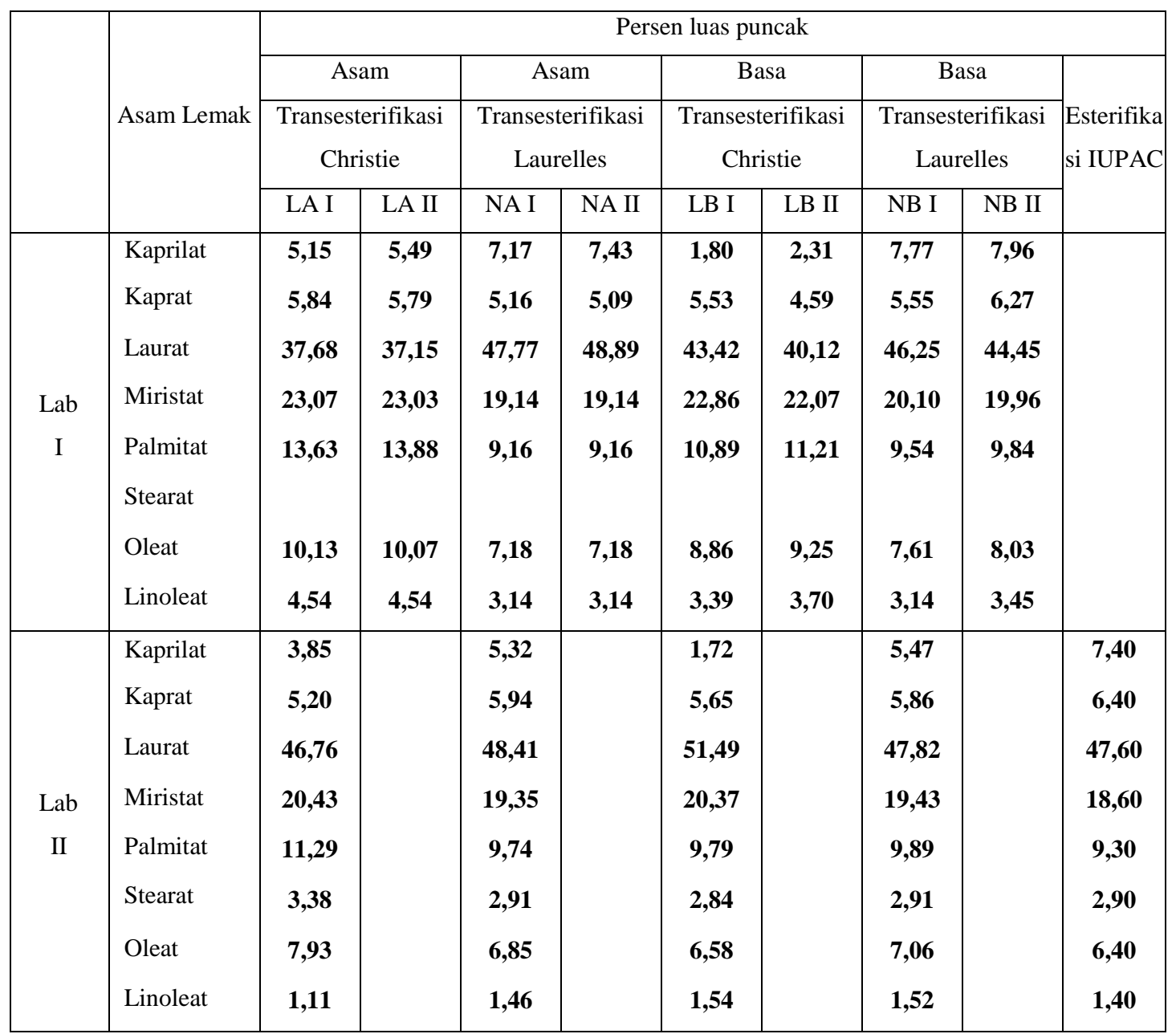

Persen luas puncak dari asam kaprilat yang diperoleh pada metode esterifikasi IUPAC cukup tinggi yaitu $7,4 \%$. Hal ini disebabkan karena $\mathrm{BF}_{3}$ metanol merupakan asam lewis dalam wujud koordinasi kompleks dengan metanol menjadikannya sebagai katalis asam yang kuat (Christie, 1993).

Kelima metode yang digunakan yaitu transesterifikasi asam dan basa (Christie, 1993), transesterifikasi asam dan basa (Laureles, 2002) dan esterifikasi (IUPAC, 1997) menggunakan perlakuan yang berbeda tetapi tidak menunjukkan adanya asam kaproat. Hal ini disebabkan karena asam kaproat merupakan asam lemak rantai pendek yang mudah menguap dan cenderung mudah larut dalam air, sehingga pada waktu pemanasan dan pada waktu diekstraksi dengan air dapat menghilangkan komposisi asam kaproat yang relatif sedikit.

\section{KESIMPULAN}

1. Dari kedua laboratorium ( Lab 1 dan 2 ) yang digunakan untuk menganalisa komposisi asam lemak diperoleh waktu retensi yang bervariasi, selanjutnya untuk asam stearat tidak teranalisis pada lab 1 .

2. Luas puncak asam lemak untuk masing masing laboratorium sangat jauh berbeda 
yang mungkin disebabkan kurang teroptimasinya operasi peralatan kromatografi gas.

3. Asam lemak kaprilatmempunyai persen luas puncaklebih tinggi pada laboratorium 1 dari pada yang diperoleh di laboratorium 2; dan persen luas puncak asam lemak kaprat yang diperoleh pada kedua laboratorium hampir sama.

4. Hasil penelitian ini menunjukkan kedua alat tersebut mempunyai kelebihan dan kekurangan masing-masing ; pada laboratorium 1 tidak semua asam lemak muncul, tapi garis dasarnya sangat baik, dan laboratorium 2 semua asam lemak muncul, tapi garis dasarnya kurang baik.

\section{DAFTAR PUSTAKA}

Anonim.2004. APCC Standards for virgin coconut oil. www.apccsec.org/ document [17 Maret 2006]

Christie, W. 1993.Preparation of Ester Derivates of Fatty Acids for Chromatography Analysis. Advance in Lipid Methodology. Ed. W. W. Christie. Oily Press.Dundee, Scotland.

Hendayana, S., A. Kodarohman, A.A. Sumarna, dan A. Supriana. 1994. Kimia Analitik Instrumen. IKIP Semarang press, Semarang.

IUPAC. 1987. Standard Methods for the analysis of oils, fats and Derivates $7^{\text {th }}$ Edition, International Union of Pure and Aplied Chemistry, Consorsium on Oils, Fats and Derivates. Backwell Scientificts Publication Oxford, England.

Ketaren, S .1986. Pengantar Teknologi Minyak dan Lemak Pangan. UIPress Jakarta.

Khopkar, S. M. 1990. Konsep Dasar Kimia Analitik. Universitas Indonesia, Jakarta.
Laurelles,L. R., F. M. Rodriguez., C. E. Reano., G. A. Santos., A. C. Laurena., E. M. T. Mendoza. 2002. Variability in Fatty Acid and Triacilglycerol Composition of the Oil of Coconut (Coconut nucifera L.) Hybrids and Their Parentals. . J. Agric. Food Chem. 50 : $1581-1586$

Robards, K., Haddad, P.R., and Jackson, P. 1994.Principles and practice of modern chromatographic methods.Academic Press, Australia.

Sutarmi.,H. Rozaline.2005. Taklukkan Penyakit Dengan VCO. Penebar Swadaya,Jakarta.

Winarno, F.G. 2002. Kimia Pangan Dan Gizi. PT. Gramedia Pustaka Utama, Jakarta.
Zapsalis, C., R. Beck. 1996. Food Chemistry and Nutritional Biochemistry. Macmillan Publishing Company, New York.

